\title{
Thermophilic phosphoribosyltransferases Thermus thermophilus HB27 in nucleotide synthesis
}

\author{
Ilja V. Fateev, Ekaterina V. Sinitsina, Aiguzel U. Bikanasova, Maria A. Kostromina, \\ Elena S. Tuzova, Larisa V. Esipova, Tatiana I. Muravyova, Alexei L. Kayushin, \\ Irina D. Konstantinova* and Roman S. Esipov*
}

\author{
Full Research Paper \\ Address: \\ Shemyakin and Ovchinnikov Institute of Bioorganic Chemistry, \\ Miklukho-Maklaya Str., 16/10, Moscow, GSP-7, 117997, Russia \\ Email: \\ Irina D. Konstantinova* - kid1968@yandex.ru; Roman S. Esipov* - \\ esipov@ibch.ru \\ * Corresponding author \\ Keywords: \\ adenine phosphoribosyltransferase; catalysis; enzyme; hypoxanthine \\ phosphoribosyltransferase; multi-enzyme cascade; nucleotides; \\ thermophiles
}

\author{
Beilstein J. Org. Chem. 2018, 14, 3098-3105. \\ doi:10.3762/bjoc. 14.289 \\ Received: 05 July 2018 \\ Accepted: 27 November 2018 \\ Published: 21 December 2018 \\ This article is part of the thematic issue "Enzymes in chemical \\ transformations". \\ Guest Editor: K. N. Allen \\ (c) 2018 Fateev et al.; licensee Beilstein-Institut. \\ License and terms: see end of document.
}

\begin{abstract}
Phosphoribosyltransferases are the tools that allow the synthesis of nucleotide analogues using multi-enzymatic cascades. The recombinant adenine phosphoribosyltransferase (TthAPRT) and hypoxanthine phosphoribosyltransferase (TthHPRT) from Thermus thermophilus HB27 were expressed in E.coli strains and purified by chromatographic methods with yields of 10-13 mg per liter of culture. The activity dependence of TthAPRT and TthHPRT on different factors was investigated along with the substrate specificity towards different heterocyclic bases. The kinetic parameters for TthHPRT with natural substrates were determined. Two nucleotides were synthesized: 9-( $\beta$-D-ribofuranosyl)-2-chloroadenine 5'-monophosphate (2-Cl-AMP) using TthAPRT and 1-( $\beta$-Dribofuranosyl)pyrazolo[3,4- $d$ ]pyrimidine-4-one 5'-monophosphate (Allop-MP) using TthHPRT.
\end{abstract}

\section{Introduction}

Bacterial phosphoribosyltransferases are used in multi-enzymatic cascades that perform nucleotide synthesis de novo [1,2]. Recently, we reported on the possibility of cascade synthesis, where enzymes of thermophilic microorganisms Thermus thermophilus HB27 (phosphoribosylpyrophosphate synthetase PRPPS and adenine phosphoribosyltransferase - APRT) and Thermus sp. 2.9 (ribokinase - RK) carry out successive transformations of ribose and adenine heterocyclic bases into the corresponding nucleotides (Figure 1). The use of thermophilic phosphoribosyltransferases allows carrying out reactions at a higher temperature, so the concentrations of heterocyclic bases can be increased [1-3].

There is great interest in the development of multi-enzymatic cascades [4-9] for the preparation of nucleosides and nucleotides due to the regio- and stereospecificity of enzymes 


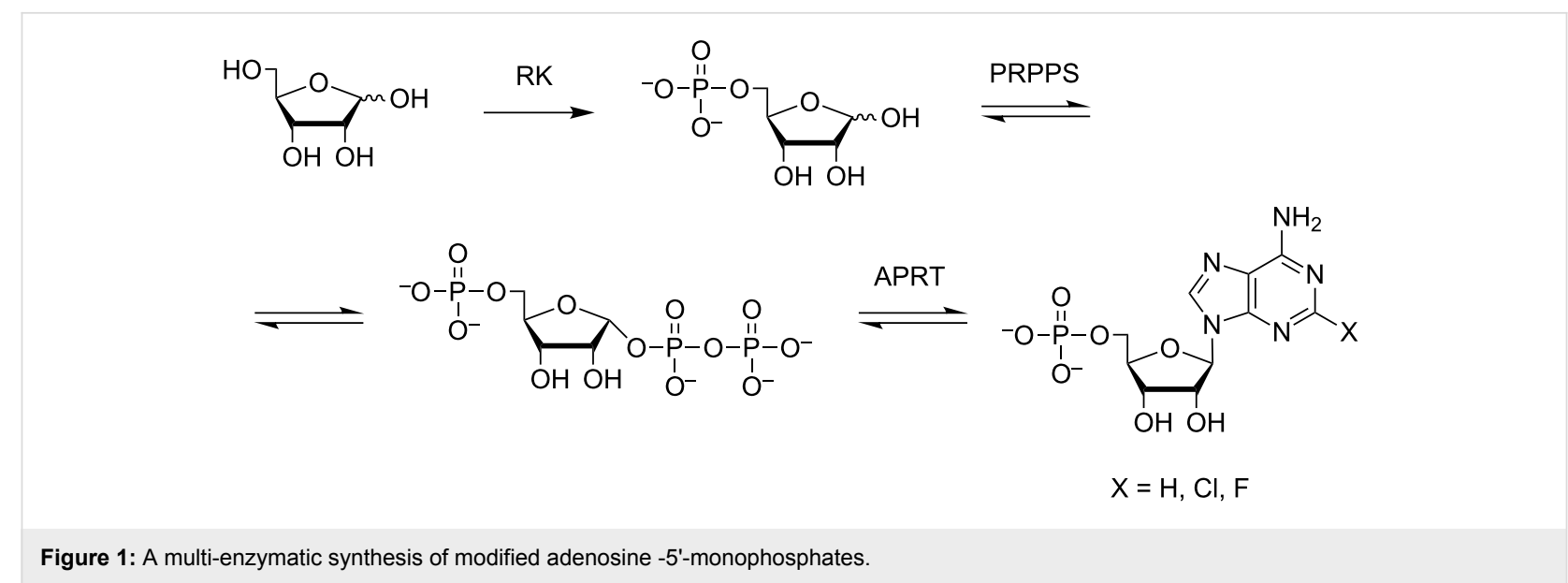

$[4,10,11]$, performing metabolic transformations of substrates. Phosphoribosyltransferases are increasingly being widely used as key enzymes in multi-enzymatic systems [2]. The substrate specificity of APRT limits the number of possible nucleotides that can be synthesized. Thus, for Thermus thermophilus HB27 APRT (TthAPRT), nucleotide synthesis is limited to the closest structural homologs of adenine (Table 1) [1].

\begin{tabular}{|c|c|}
\hline Base & $\begin{array}{l}\text { Conversion into nucleotide } \\
(24 \mathrm{~h}, \%)^{\mathrm{a}}\end{array}$ \\
\hline 2,6-diaminopurine & 16.80 \\
\hline 2-chloroadenine & 97.58 \\
\hline 2-fluoroadenine & 36.50 \\
\hline adenine & 50.02 \\
\hline 2-methoxyadenine & 60.88 \\
\hline N1-methyladenine & 78.2 \\
\hline N6-benzyladenine & 1.87 \\
\hline 2-aminobenzimidazole & 0.09 \\
\hline \multicolumn{2}{|c|}{ 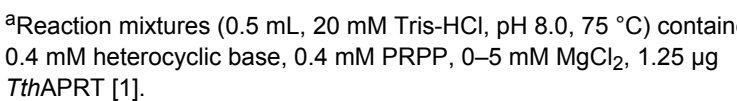 } \\
\hline
\end{tabular}

Unfortunately, 1,2,4-triazole-3-carboxamide, its analogues, guanine, hypoxanthine, and 7-deazapurins are not substrates for TthAPRT. This severely limits the usability of multi-enzymatic cascades in the synthesis of nucleotides, including the modified ones.

To expand the possible repertoire of nucleotides that could be synthesized, we obtained the recombinant form of hypoxathine phosphoribosyltransferase Thermus thermophilus (TthHPRT), investigated its substrate specificity and optimal conditions for catalytic activity, and determined the kinetic parameters of the enzyme. A comparative study of the substrate specificity of
TthAPRT and TthHPRT was performed to determine the usability of thermophilic transferases in nucleotide synthesis. A scheme of purine nucleotide synthesis using TthAPRT and TthHPRT is shown in Figure 2.

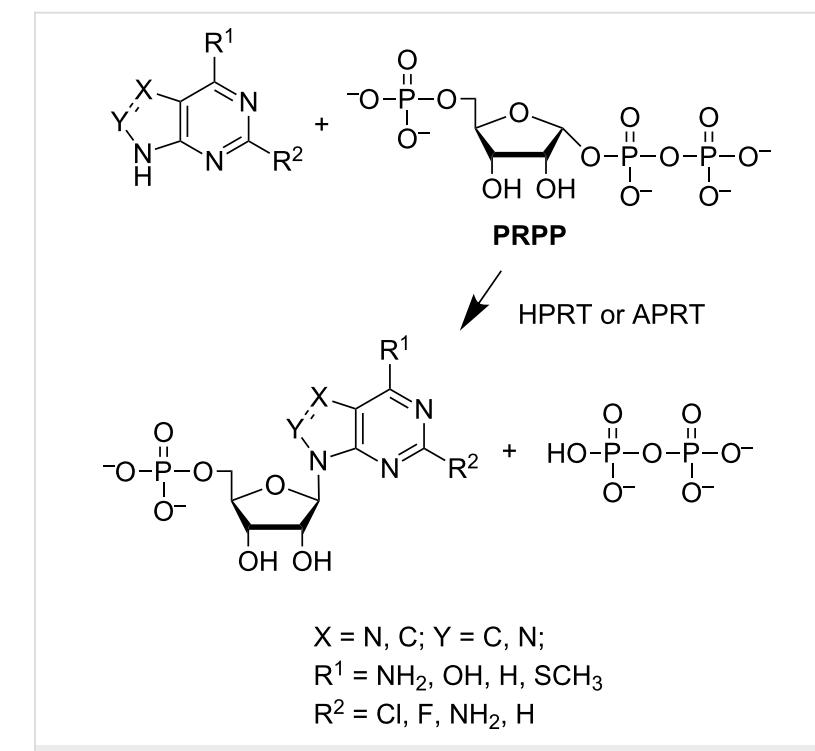

Figure 2: Nucleotide synthesis using phosphoribosyltransferases.

\section{Results and Discussion}

Genes TT_RS08985 and TT_RS06315 from T. thermophilus HB27, coding TthHPRT and TthAPRT, were cloned into expression plasmid vectors pET $23 \mathrm{a}+$ and $\mathrm{pET} 23 \mathrm{~d}+$, respectively. The resulting recombinant plasmid pER-TthHPRT contained fusion gene HPRT-HisTag coding TthHPRT with a C-terminal His-Tag. The resulting recombinant plasmid pERTthAPRT contained the gene APRT coding TthAPRT without any additional sequences. Nucleotide sequences of the cloned genes were verified by sequencing. The codone $\mathrm{GGG} \rightarrow \mathrm{AGG}$ substitution corresponding to amino-acid Arg27Gly replacement was found in the gene encoding the TthHPRT. 
The screening of available producer strains was performed to find strains, which produce target enzymes in soluble form. The resulting strains $E$. coli BL21(DE3)/pER- TthAPRT and E. coli C3030/pER- TthHPRT produced enzymes mainly in soluble form $(>80 \%)$.

The established procedure for isolation and purification of TthHPRT includes heat treatment, immobilized metal affinity chromatography, final size-exclusion chromatography, and concentration. For TthAPRT, the protocol include heat treatment, anion exchange chromatography, hydrophobic chromatography, final size-exclusion chromatography, and concentration. Yields of both transferases were no less than 10-13 mg per liter of culture, with a purity of about $96 \%$ (as determined by SDSPAGE).

The influence of temperature and $\mathrm{Mg}^{2+}$ concentration on the activity of TthHPRT was investigated. The results were compared with data for adenine phosphoribosyltransferase Thermus thermophilus, obtained earlier [1].

The TthAPRT is active over a wide temperature range (Figure 3). A maximal activity of TthHPRT (1.1 unit $/ \mathrm{mg}$ ) is observed at $60{ }^{\circ} \mathrm{C}$. The activity at $36{ }^{\circ} \mathrm{C}$ is $5 \%$ from the maximal one and at $90{ }^{\circ} \mathrm{C}$ it is $3 \%$ from the maximal one. It is interesting, that TthAPRT shows its maximal activity at $75^{\circ} \mathrm{C}$.

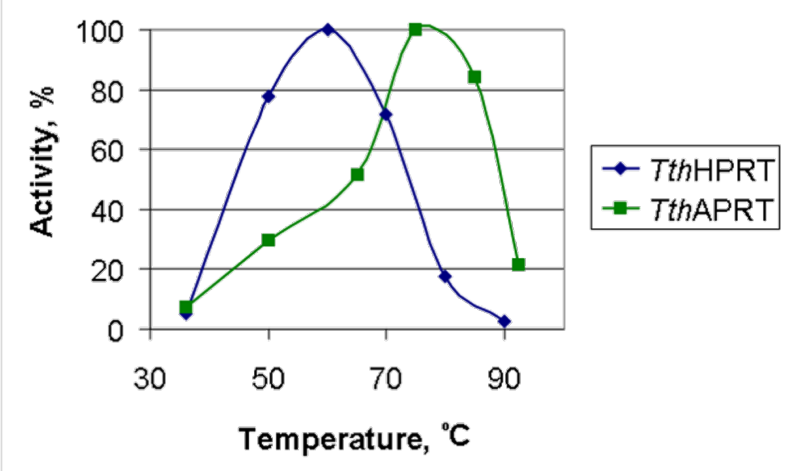

Figure 3: Dependence of ThHPRT and TthAPRT activity on temperature (reaction mixtures $(0.5 \mathrm{~mL})$ contained $20 \mathrm{mM}$ Tris- $\mathrm{HCl}, \mathrm{pH} 8.0$, $1 \mathrm{mM} 5$-phosphoribosyl-1- $\alpha$-pyrophosphate, and $5 \mathrm{mM} \mathrm{MgCl}_{2}$; in the case of ThHPRT mixtures contained $1 \mathrm{mM}$ hypoxanthine and $0.18 \mu \mathrm{g}$ of enzyme, in the case of ThAPRT - $1 \mathrm{mM}$ adenine and $0.125 \mu \mathrm{g}$ of enzyme).

The influence of the magnesium ion concentration on the TthHPRT activity is nonlinear. The activity increases rapidly while the magnesium chloride concentration increases from 0 to $1 \mathrm{mM}$ (Figure 4). Further increasing of the concentration (up to $5 \mathrm{mM}$ ) does not increase the activity significantly. Since the reaction rate increases rapidly with increasing the magnesium chloride concentration to values equivalent to the concentration of 5-phosphoribosyl- $\alpha$-1-pyrophosphate ( $1 \mathrm{mM})$, it can be assumed that the presence of magnesium ions promotes the proper spatial orientation of the substrate. The reaction also proceeds in the absence of magnesium ions in solution. A similar dependence is observed for TthAPRT.

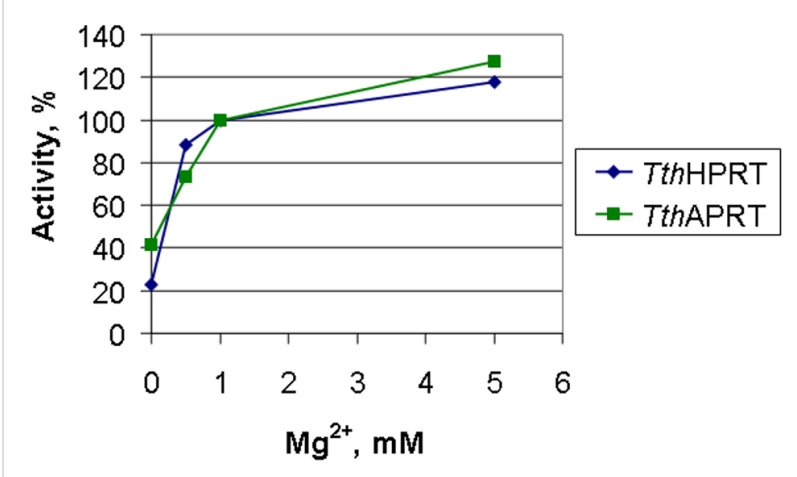

Figure 4: Dependence of TthHPRT and TthAPRT activity on the $\mathrm{Mg}^{2+}$ concentration (reaction mixtures $(0.5 \mathrm{~mL})$ contained $20 \mathrm{mM}$ Tris- $\mathrm{HCl}$, $\mathrm{pH}$ 8.0, 1 mM 5-phosphoribosyl-1-a-pyrophosphate, and 0-5 mM $\mathrm{MgCl}_{2}$; in case of TthHPRT mixtures contained $1 \mathrm{mM}$ hypoxanthine and $0.18 \mu \mathrm{g}$ of enzyme, in case of ThAPRT $-1 \mathrm{mM}$ adenine and $0.125 \mu \mathrm{g}$ of enzyme; reactions were performed at $70{ }^{\circ} \mathrm{C} ; 100 \%$ - activity at $1 \mathrm{mM}$ concentration).

After optimization of the reaction conditions, kinetic parameters for TthHPRT were determined (Table 2).

Based on the $K_{\mathrm{m}}$ values, the affinity of 5-phosphoribosyl- $\alpha-1$ pyrophosphate for the active site is much lower than that of heterocyclic bases. The similar situation we observed for TthAPRT [1]. Comparison of the synthesis rates of inosine-5'monophosphate and guanosine-5'-monophosphate showed that the first is synthesized 4.6 times faster. The literature data for similar enzymes (see Table 2) confirm a poor affinity of PRPP to the active site: $K_{\mathrm{m}}$ for hypoxanthine is 17 fold less then for PRPP, although for the human enzyme $K_{\mathrm{m}}$ is only 5 fold less. Comparing two enzymes from different strains of Thermus thermophilus, we can conclude that TthAPRT from HB8 (in contrast with HB27), synthesizes guanosine-5`-monophosphate faster. This may be due to the difference in reaction conditions. Kinetic data are displayed by double reciprocal plot (Figure 5). Determination of substrate specificity of TthHPRT was performed in comparative experiments with TthAPRT. The process of nucleotide synthesis was monitored by a liquid chromatography-mass spectrometry analysis of the reaction mixture.

The data is presented in the Table 3. As expected, TthHPRT is specific to 6-oxopurines, while TthAPRT is specific to 6-aminopurines. Both enzymes do not recognize thymine as a substrate. This is consistent with data that pyrimidine heterocyclic bases are substrates for uracyl phosphoribosyltransferase 
Table 2: Kinetic parameters of inosine-5'-monophosphate and guanosine-5'-monophosphate synthesis using HPRT from various organisms.

\begin{tabular}{|c|c|c|c|c|}
\hline Substrate & $K_{\mathrm{m}}, \mu \mathrm{M}$ & $V_{\max }, \mu \mathrm{mol} / \mathrm{min} \cdot \mathrm{mg}$ & $k_{\text {cat }}, 1 / \mathrm{s}$ & $k_{\text {cat }} / K_{\mathrm{m}}, 1 / \mathrm{M} \cdot \mathrm{s}$ \\
\hline \multicolumn{5}{|c|}{ Thermus thermophilus HB27 } \\
\hline hypoxanthine & $13 \pm 4$ & $28 \pm 9$ & $9 \pm 3$ & $6.9 \times 10^{5}$ \\
\hline guanine & $28 \pm 9$ & $6 \pm 2$ & $2.0 \pm 0.7$ & $7.1 \times 10^{4}$ \\
\hline PRPP & $220 \pm 60$ & $17 \pm 5$ & $6 \pm 2$ & $2.7 \times 10^{4}$ \\
\hline \multicolumn{5}{|c|}{ Thermus thermophilus HB8 [12] } \\
\hline hypoxanthine & $3.9 \pm 1.5$ & - & $9.1 \pm 0.8$ & - \\
\hline guanine & $7.4 \pm 1.7$ & - & $18 \pm 1$ & - \\
\hline PRPP & $68 \pm 18$ & - & $20 \pm 2$ & - \\
\hline \multicolumn{5}{|c|}{ Homo sapiens [13] } \\
\hline hypoxanthine & $3.8 \pm 0.3$ & - & $2.6 \pm 0.6$ & $7 \times 10^{5}$ \\
\hline PRPP & $19.1 \pm 1.6$ & - & $2.5 \pm 0.05$ & $1 \times 10^{5}$ \\
\hline \multicolumn{5}{|c|}{ Escherichia coli [14] } \\
\hline Hypoxanthine & 37 & - & - & - \\
\hline PRPP & 330 & - & - & - \\
\hline
\end{tabular}

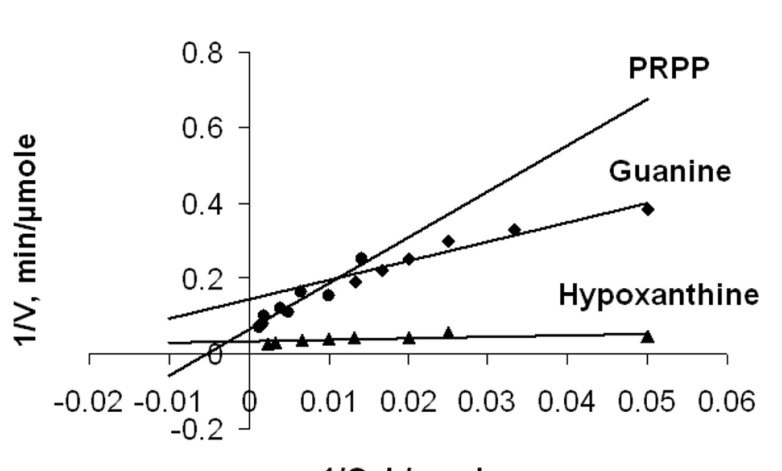

$1 / \mathrm{C}, \mathrm{L} / \mu \mathrm{mole}$

Figure 5: Lineweaver-Burk plot for synthesis of inosine-5'-monophosphate and guanosine-5'-monophosphate.

and orotate phosphoribosyltransferase only [2]. Unfortunately, we did not find any product in reactions with compounds based on 1,2,4-triazole-3-carboxamide, which was also observed for E. coli HPRT $[15,16]$. However, allopurinol and 8-azaguanine are substrates for TthHPRT, and 2-chloroadenine is a substrate for TthAPRT. For 2-chloroadenine and 8-azaguanine, reaction at a higher temperature is preferable because of their low solubility in water (less than $1 \mathrm{mM}$ at $37^{\circ} \mathrm{C}$ ). Interestingly, allopurinol proved to be a good substrate for both TthHPRT and TthAPRT, unlike hypoxanthine, which differs only in the position of one of the nitrogen atoms. Probably, the presence of nitrogen atom at $\mathrm{C} 7$ position of purine heterocycles plays an important role in reactions catalyzed by phosphoribosyltransferase, and also affects the substrate properties of TthHPRT and TthAPRT.
Table 3: Substrate specifity of TthHPRT and TthAPRT.

\begin{tabular}{|c|c|c|}
\hline \multirow[t]{2}{*}{ Base } & \multicolumn{2}{|c|}{ Conversion $(24 \mathrm{~h}, \%)^{\mathrm{a}}$} \\
\hline & TthHPRT & TthAPRT \\
\hline adenine & 5.3 & 48.1 \\
\hline hypoxanthine & 91.0 & 6.4 \\
\hline guanine & 73.9 & 25.6 \\
\hline 2-chloroadenine & 0 & 52.9 \\
\hline 2-fluoroadenine & 0 & 31.1 \\
\hline 6-mercapopurine & 85.1 & 4.8 \\
\hline allopurinol & 39.3 & 57.4 \\
\hline 8-azaguanine & 80.6 & 1.0 \\
\hline thymine & 0 & 0 \\
\hline 1,2,4-triazole-3-carboxamide & 0 & 0 \\
\hline $\begin{array}{l}\text { 1,2,4-triazole-3-carboxy- } N \text {-methyl- } \\
\text { amide }\end{array}$ & 0 & 0 \\
\hline
\end{tabular}

Two nucleotides were synthesized using TthHPRT or TthAPRT (see Figure 6). Synthesis of 2-Cl-AMP was performed at $75^{\circ} \mathrm{C}$. This allowed to achieve a concentration of $0.5 \mathrm{mM}$ of the initial 2 -chloroadenine. The reaction progress was monitored by HPLC. After 2 days (the product content in the reaction mixture was 54\%), the reaction mixture was concentrated and the desired product was isolated by column chromatography on ionexchange sorbents (anion and then cation-exchange). The yield of 2-Cl-AMP was $37 \%$. A second nucleotide (Allop-MP) was synthesized at a lower temperature $\left(60^{\circ} \mathrm{C}\right)$. After 2 days, the product content in the reaction mixture was $55 \%$. The product was isolated in the same way, with a yield of $32 \%$. 


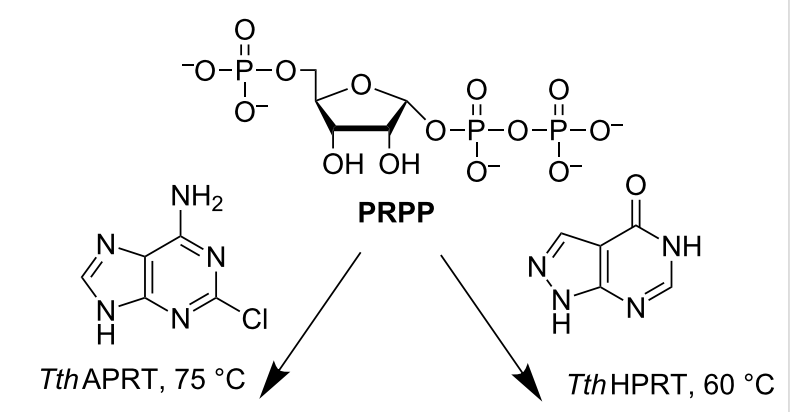<smiles>Nc1nc(Cl)nc2c1ncn2[C@@H]1O[C@H](COP(=O)([O-])[O-])[C@@H](O)[C@H]1O</smiles>

2Cl-AMP

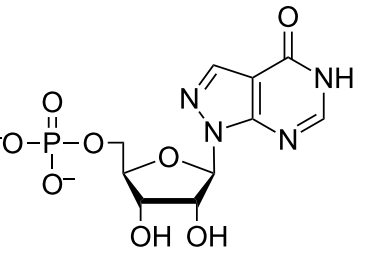

Allop-MP
Figure 6: Synthesis of nucleotides 2Cl-AMP and Allop-MP using phosphoribosyltransferases TthAPRT or TthHPRT respectively.

\section{Conclusion}

The recombinant adenine phosphoribosyltransferase and hypoxanthine phosphoribosyltransferase from Thermus thermophilus HB27 were purificated with yields no less than 10-13 mg per litre of culture. A comparative study of substrate specificity of these enzymes towards different heterocyclic bases was carried out and temperature-dependence and magnesium chloride concentration-dependence of enzymes activity were determined. TthHPRT can be used for the synthesis of nucleotides containing different purine derivatives including 8-aza- and 8-aza-7deazapurine. The use of hypoxanthine and adenine transferases in multi-enzyme cascades significantly extends the spectrum of synthetic purine nucleotides. Two nucleotides were synthesized: 9-( $\beta$-D-ribofuranosyl)-2-chloroadenine 5'-monophosphate (2-Cl-AMP) using TthAPRT and 1-( $\beta$-D-ribofuranosyl)pyrazolo[3,4- $d]$ pyrimidine-4-one 5'-monophosphate (Allop-MP) using TthHPRT with yields of $37 \%$ and $32 \%$, respectively. Using of hypoxanthine and adenine transferases in multi-enzyme cascades significantly extends the spectrum of synthetic purine nucleotides.

\section{Experimental}

Tris-buffer, acetic acid, sodium chloride, glycerol, acrylamide, $N, N$ '-bisacrylamide, ATP, bromophenol blue, agarose, EDTA, IPTG, ampicillin, sodium dodecylsulfate, imidazole and DMF were purchased from Panreac (Spain, Barselona). Ethanol was purchased from MedChemProm. Coomassie Brilliant Blue R-250 was purchased from Bio-Rad (USA, CA). Bacto yeast extract, bacto tryptone, and bacto agar were purchased from
Becton Dickinson Biosciences (USA, NJ). $\mathrm{NaOH}$ and $\mathrm{HCl}$ were purchased from Merck (USA, MA). Sodium persulfate, TEMED, ethidium bromide, and sodium azide were purchased from Helicon (Russia). dNTP was purchased from Thermo Fisher Scientific (USA, MA). DTT, phenylmethylsulfonyl chloride, magnesium chloride, nickel sulfate, potassium dihydroorthophosphate, Ni-IDA sepharose, 5-phosphoribosyl- $\alpha-1$ pyrophosphate and all bases (adenine, hypoxanthine, guanine, 2-chloroadenine, etc.) were purchased from Sigma-Aldrich (USA, MO).

Bacterial strains: a) E. coli $\mathrm{C} 3030$ [MiniF lys $Y\left(\mathrm{Cam}^{\mathrm{R}}\right) /$ fhuA2 lacZ::T7 gene1 [lon] ompT ahpC gal גatt::pNEB3-r1-cDsbC $\left(\mathrm{Spec}^{\mathrm{R}}, \operatorname{lacI}^{\mathrm{q}}\right) \Delta$ trxB sulA11 R(mcr-73::miniTn10--Tet $\left.{ }^{\mathrm{S}}\right) 2$ [dcm] $R\left(z g b-210: \because \operatorname{Tn} 10--\mathrm{Tet}^{\mathrm{S}}\right)$ endA1 $\Delta$ gor $\Delta($ mcrC-mrr $\left.) 114:: I S 10\right]$ New England Biolabs (USA, MA), b) E.coli BL21(DE3) fhuA2 [lon] ompT gal ( $\lambda$ DE3) [dcm] $\triangle h s d S \lambda D E 3=\lambda$ sBamHIo $\triangle E$ coRI-B int::(lacI::PlacUV5::T7 gene1) i21 Anin5.

Plasmid vector: pET 23a+, pET 23d+ (Merck Millipore, USA, MA).

Enzymes: NdeI, XhoI, NcoI, T4 DNA-ligase (Thermo Scientific, USA, MA), Encyclo-polymerase (Eurogen, Russia).

The protein concentration was determined by the Bradford method [17], using BSA as a standard.

Protein purity was determined by electrophoresis in a polyacrylamide gel under denaturing conditions [18].

Cloning and creation of producer strain: Genes TT_RS08985 and TT_RS06315, encoding TthHPRT and TthAPRT, respectively, were amplified on the genomic DNA template of the T. thermophilus HB27 strain by a polymerase chain reaction (PCR) using synthetic primers. The genes were cloned into the expression vectors $\mathrm{pET}-23 \mathrm{a}+$ and $\mathrm{pET}-23 \mathrm{~d}+$ respectively. The E. coli strains BL21(DE3)/pER- TthAPRT and C3030/pER- TthHPRT produced the target enzymes mainly in soluble form (culturing conditions: $4 \mathrm{~h}$ grow at $37{ }^{\circ} \mathrm{C}$ after supplementing with $0.4 \mathrm{mM}$ IPTG).

Isolation and purification of TthHPRT: A cell pellet was resuspended in $50 \mathrm{mM}$ Tris- $\mathrm{HCl}, 200 \mathrm{mM} \mathrm{NaCl}$, and $1 \mathrm{mM}$ phenylmethylsulfonyl fluoride (PMSF) pH $8.0(1: 10 \mathrm{w} / \mathrm{v})$. The cells were disrupted by sonication for $30 \mathrm{~min}$ at $20 \mathrm{kHz}$ at $+4{ }^{\circ} \mathrm{C}$. The cell debris was pelleted by centrifugation at $12,000 \mathrm{rpm}$ for $30 \mathrm{~min}$ at $+4{ }^{\circ} \mathrm{C}$. The cell lysate was heat-treated $\left(65^{\circ} \mathrm{C}, 10 \mathrm{~min}\right)$ and the pellet was removed by centrifugation. The supernatant was applied to a column XK 16/20 (GE Healthcare, USA) packed with Ni-IDA Sepharose (Sigma Aldrich, 
USA) pre-equilibrated with $50 \mathrm{mM}$ Tris- $\mathrm{HCl}$ and $200 \mathrm{mM} \mathrm{NaCl}$ at $\mathrm{pH}$ 8.0. Ballast proteins were eluted with a solution, containing $50 \mathrm{mM}$ Tris- $\mathrm{HCl}, 50 \mathrm{mM}$ imidazole, and $200 \mathrm{mM} \mathrm{NaCl}$, $\mathrm{pH} 8.0$ (4 CV, flow rate $2 \mathrm{~mL} / \mathrm{min}$ ). The target enzyme was eluted with solution, contained $50 \mathrm{mM}$ Tris- $\mathrm{HCl}, 250 \mathrm{mM}$ imidazole, and $200 \mathrm{mM} \mathrm{NaCl}, \mathrm{pH} 8.0$ (4 CV, flow rate $2 \mathrm{~mL} / \mathrm{min}$ ). Pooled fractions were concentrated by a polysulfonic membrane PBGC $10 \mathrm{kDa}$ (Millipore, USA). The resulting solution was applied to a column with HiLoad 16/60 Superdex 75pg (GE Healthcare, USA), equilibrated by $20 \mathrm{mM}$ Tris- $\mathrm{HCl}, 50 \mathrm{mM} \mathrm{NaCl}, 0.04 \% \mathrm{NaN}_{3}$, and $10 \%$ glycerol, $\mathrm{pH}$ 8.0. Fractions, containing the target enzyme with a purity of more than $96 \%$, were pooled and concentrated up to a concentration of $13 \pm 1 \mathrm{mg} / \mathrm{mL}$.

Isolation and purification of TthAPRT: Cell biomass disruption and heat-treatment was performed as described in section "Isolation and purification of TthHPRT". The resulting solution was diluted (2-fold) with solution, comtained $50 \mathrm{mM}$ Tris- $\mathrm{HCl}$, $2 \mathrm{M}\left(\mathrm{NH}_{4}\right)_{2} \mathrm{SO}_{4}, \mathrm{pH} 8.0$, and applied to column XK 16/20 packed with Phenyl Sepharose HP (GE Healthcare, USA). The column was eluted by linear gradient of $\left(\mathrm{NH}_{4}\right)_{2} \mathrm{SO}_{4}(1.0-0 \mathrm{M}$, $12 \mathrm{CV}$, flow rate $2 \mathrm{~mL} / \mathrm{min}$ ). Fractions, contained the target enzyme, were pooled and concentrated on polysulphonic membrane PBGC $10 \mathrm{kDa}$. The resulting solution was applied to column with HiLoad 16/60 Superdex 200, equilibrated by $20 \mathrm{mM}$ Tris- $\mathrm{HCl}, 50 \mathrm{mM} \mathrm{NaCl}, 0.04 \% \mathrm{NaN}_{3}$, and $5 \%$ glycerol, $\mathrm{pH} 8.0$. Fractions, contained the target enzyme with purity more than $96 \%$, were pooled and concentrated up to concentration $12 \pm 1 \mathrm{mg} / \mathrm{mL}$.

Enzyme assay: Each reaction mixture $(0.5 \mathrm{~mL}, 20 \mathrm{mM}$ Tris$\mathrm{HCl}, \mathrm{pH}$ 8.0) contained $1 \mathrm{mM}$ 5-phosphoribosyl-1- $\alpha$-pyrophosphate, $1 \mathrm{mM}$ hypoxanthine, $5 \mathrm{mM} \mathrm{MgCl}$, and hypoxanthine phosphoribosyltransferase Thermus thermophilus $(0.18 \mu \mathrm{g})$. Reaction mixtures were incubated at $70{ }^{\circ} \mathrm{C}$. Substrate and product quantities were determined using HPLC (Waters 1525, column Ascentis Express C18, $2.7 \mu \mathrm{m}, 3.0 \times 75 \mathrm{~mm}$, eluent A $0.1 \%$ aqeous TFA, eluent B $0.1 \%$ TFA / $70 \%$ acetonitrile in water, detection at $254 \mathrm{~nm}$, Waters 2489).

Kinetic parameters determination: Each reaction mixture (1.0 mL, $20 \mathrm{mM}$ Tris-HCl, $\mathrm{pH}$ 8.0) contained $5 \mathrm{mM} \mathrm{MgCl}_{2}$, hypoxanthine phosphoribosyltransferase Thermus thermophilus $(0.18 \mu \mathrm{g})$, and the following components: a) hypoxanthine $(0.01-0.50 \mathrm{mM})$ or guanine $(0.01-0.20 \mathrm{mM})$ and $1 \mathrm{mM} 5$-phosphoribosyl-1- $\alpha$-pyrophosphate to determine $K_{\mathrm{m}}$ and $V_{\max }$ for hypoxanthine and guanine, and b) 5-phosphoribosyl-1- $\alpha$ pyrophosphate $(0.05-1.20 \mathrm{mM})$ and $0.50 \mathrm{mM}$ hypoxanthine to determine $K_{\mathrm{m}}$ and $V_{\max }$ for 5-phosphoribosyl-1- $\alpha$-pyrophosphate. Reaction mixtures were incubated at $70{ }^{\circ} \mathrm{C}$ for $2 \mathrm{~min}$.
Product quantities were determined as described in the "Enzyme assay" section. Each experiment was repeated three times. Kinetic parameters were determined by nonlinear regression analysis using SciDAVis v0.2.4 software (free software, web site: scidavis.sourceforge.net). Catalytic constants $\left(k_{\text {cat }}\right)$ were calculated per 1 subunit $(20.3 \mathrm{kDa}$, calculated based on amino acid sequence).

Mass spectra were measured on an Agilent 6224, ESI-TOF, LC/MS (USA) in positive ion mode (ESI), LCQ Fleet ion trap mass spectrometer (Thermo Electron, USA) and Agilent 1100 LC/MSD VL (Agilent Technologies) equipped an APCI and ESI source (positive and negative mode of ionization), 1100 DAD and ELSD PL-ELS 1000 (Polymer Laboratories).

\section{Nucleotides synthesis}

9-( $\beta$-D-Ribofuranosyl)-2-chloroadenine 5'-monophosphate (2-Cl-AMP): 2-Chloroadenine $(17 \mathrm{mg}, 0.10 \mathrm{mmol})$ was dissolved in water $(203 \mathrm{~mL})$ under stirring and heating at $90{ }^{\circ} \mathrm{C}$, and after cooling to $70{ }^{\circ} \mathrm{C}$, magnesium chloride hexahydrate (41 $\mathrm{mg}, 0.21 \mathrm{mmol}$ ) and potassium dihydroorthophosphate ( $276 \mathrm{mg}, 2.03 \mathrm{mmol}$ ) were added. The $\mathrm{pH}$ of the solution was adjusted to 8.0 by $2 \mathrm{~N}$ potassium hydroxide. The pentasodium salt of 5-phosphoribosyl- $\alpha$-1-pyrophosphate (70 mg, $0.14 \mathrm{mmol}$ ) and TthAPRT (5 units) were added, and the reaction mixture was incubated at $75{ }^{\circ} \mathrm{C}$ for 2 days; the reaction progress was monitored by HPLC. The reaction mixture was neutralized with $2 \mathrm{~N}$ hydrochloric acid and concentrated in vacuo to ca. $10 \mathrm{~mL}$. The precipitate was filtered off, the filtrate was applied to the column with DEAE-Toyopearl 650C, bicarbonate form, $40 \times 140 \mathrm{~mm}$, and the product was eluted with triethylammonium bicarbonate $(0.1 \mathrm{M})$. Fractions were concentrated in vacuo to ca. $10 \mathrm{~mL}$, applied to the column with CM-Sephadex C-25, sodium form, $20 \times 160 \mathrm{~mm}$, and the product was eluted with water to give, after evaporation and drying in vacuo under $\mathrm{P}_{2} \mathrm{O}_{5}, 16 \mathrm{mg}(0.037 \mathrm{mmol} ; 37 \%)$ of 9-( $\beta$-D-ribofuranosyl)-2-chloroadenine 5'-monophosphate of $99 \%$ purity (HPLC). HRMS $\left(\mathrm{ESI}^{+}\right): \mathrm{m} / z[\mathrm{M}+\mathrm{H}]^{+}$calcd for $\mathrm{C}_{10} \mathrm{H}_{13} \mathrm{~N}_{5} \mathrm{O}_{7} \mathrm{P}_{1} \mathrm{Cl}_{1}$ : 382.0315; found, 382.0353; [2M + H] $]^{+}$, found, 763.0606; [Base $+\mathrm{H}]^{+}$, found, 170.0244; ${ }^{1} \mathrm{H}$ NMR $\left.\left(\mathrm{DMSO}-d_{6}\right) \delta \mathrm{ppm}\right) 8.52$ (s, 1H, H8), 7.78 (br. s., $2 \mathrm{H}, \mathrm{NH}_{2}$ ), $5.83\left(\mathrm{~d}, J_{1}{ }^{\prime}, 2^{\prime}=6 \mathrm{~Hz}, 1 \mathrm{H}, \mathrm{H} 1^{\prime}\right), 4.61$ (m, 1H, H2'), 4.23 (m, 1H, H3'), 4.06 (m, 1H, H4'), 3.84 (m, 2H, H5a', H5b') ppm; ${ }^{13} \mathrm{C}$ NMR (DMSO-d $\left.d_{6}\right) \delta 156.61$ (C2 or C6), 153.01 (C6 or C2), 150.73 (C4), 139.68 (C8), 117.57 (C5), 86.40 (C1'), 84.52 (C4'), 74.13 (C2'), 71.06 (C3'), 3.94 (C5') ppm; ${ }^{15} \mathrm{~N}$ NMR (DMSO- $\left.d_{6}\right) \delta 242.7$ (N7), 171.3 (N9), $86.84\left(\mathrm{NH}_{2}\right)$ ppm.

1-( $\beta$-D-Ribofuranosyl)pyrazolo $[3,4-d]$ pyrimidine-4-one 5'-monophosphate (Allop-MP): Allopurinol (14 mg, 
$0.10 \mathrm{mmol})$ was dissolved in water $(203 \mathrm{~mL})$ under stirring and heating at $90{ }^{\circ} \mathrm{C}$, and after cooling to $50{ }^{\circ} \mathrm{C}$, magnesium chloride hexahydrate $(41 \mathrm{mg}, 0.21 \mathrm{mmol})$ and potassium dihydroorthophosphate (276 mg, $2.03 \mathrm{mmol}$ ) were added. The $\mathrm{pH}$ of the solution was adjusted to 8.0 with $2 \mathrm{~N}$ potassium hydroxide. The pentasodium salt of 5-phosphoribosyl- $\alpha$-1-pyrophosphate (70 $\mathrm{mg}, 0.14 \mathrm{mmol}$ ) and TthHPRT ( 5 units) were added, and the reaction mixture was incubated at $60^{\circ} \mathrm{C}$ for 2 days; the reaction progress was monitored by HPLC. The reaction mixture was neutralized by $2 \mathrm{~N}$ hydrochloric acid and concentrated in vacuo to ca. $10 \mathrm{~mL}$. The precipitate was filtered off, the filtrate was placed on the column with DEAE-Toyopearl 650C, bicarbonate form, $40 \times 140 \mathrm{~mm}$, and the product was eluted with triethylammonium bicarbonate $(0.2 \mathrm{M})$. Fractions were concentrated in vacuo to ca. $10 \mathrm{~mL}$, applied to the column with CM-Sephadex C-25, sodium form, $20 \times 160 \mathrm{~mm}$, and the product was eluted with water to give, after evaporation and drying in vacuo under $\mathrm{P}_{2} \mathrm{O}_{5}, 11 \mathrm{mg}(0.032 \mathrm{mmol} ; 32 \%)$ of 1-( $\beta$-D-ribofuranosyl)pyrazolo[3,4- $d$ pyrimidine-4-one 5'-monophosphate of $97 \%$ purity (HPLC). HRMS $\left(\mathrm{ESI}^{+}\right): m / z[\mathrm{M}+\mathrm{H}]^{+}$calcd for $\mathrm{C}_{10} \mathrm{H}_{13} \mathrm{~N}_{4} \mathrm{O}_{8} \mathrm{P}_{1}$ : 349.0545; found, 349.0520; $[2 \mathrm{M}+\mathrm{H}]^{+}$, found, 697.0952; $[3 \mathrm{M}+\mathrm{H}]^{+}$, found, 1045.1374; $[\text {Base }+\mathrm{H}]^{+}$found, 137.0453; ${ }^{1} \mathrm{H}$ NMR (DMSO- $d_{6}$ ) $\delta 12.44$ (br. s, $\left.1 \mathrm{H}, \mathrm{NH}\right), 8.15$ (s, 1H, H3), 8.13 (s, 1H, H6), 6.06 (d, $J=4.1 \mathrm{~Hz}, 1 \mathrm{H}, \mathrm{H} 1$ '), 4.56 (dt, 1H, H2', $J=4.54$; <0.5), 4.31 (t, 1H, H3', $J=4.8$ ), 4.04 (m, 1H, H4'), 3.85 (ddd, $J=11.0,7.6 ; 6.2 \mathrm{~Hz}, 1 \mathrm{H}, \mathrm{H} 5$ 'a), 3.66 (ddd, $J=11.0,7.2,6.1 \mathrm{~Hz} 1 \mathrm{H}, \mathrm{H} 5$ 'b) ppm; ${ }^{13} \mathrm{C}$ NMR $\left(\mathrm{DMSO}-d_{6}\right) \delta 157.03(\mathrm{C} 4), 152.90$ (C7a), 148.53 (C6), 135.38 (C3), 106.06 (C4a), 88.16 (C1'), 83.27 (C4'), 73.39 (C2'), 71.38 (C3'), 64.76 (C5') ppm; ${ }^{15} \mathrm{~N}$ NMR (DMSO- $d_{6}$ ) $\delta 302.8$ (N2), 210.6 (N7), 204.9 (N1), 171.1 (N5).

\section{Abbreviations}

APRT - adenine phosphoribosyltransferase; HPRT hypoxathine phosphoribosyltransferase; PRPPS - phosphoribosylpyrophosphate synthetase; RK - ribokinase; Tth - Thermus thermophilus; 2-Cl-AMP - 9-( $\beta$-D-ribofuranosyl)-2-chloroadenine 5'-monophosphate; Allop-MP - 1-( $\beta$-D-ribofuranosyl)pyrazolo $[3,4-d]$ pyrimidine-4-one 5'-monophosphate

\section{Supporting Information}

\section{Supporting Information File 1}

Detailed analysis of mass spectrometry and NMR data.

[https://www.beilstein-journals.org/bjoc/content/ supplementary/1860-5397-14-289-S1.pdf]

\section{ORCID ${ }^{\circledR}$ iDs}

Ilja V. Fateev - https://orcid.org/0000-0002-8571-4197

Irina D. Konstantinova - https://orcid.org/0000-0001-5563-6549

\section{References}

1. Esipov, R. S.; Abramchik, Yu. A.; Fateev, I. V.; Konstantinova, I. D.; Kostromina, M. A.; Muravyova, T. I.; Artemova, K. G.; Miroshnikov, A. I. ActaNaturae 2016, 8, 82-90.

2. Del Arco, J.; Fernández-Lucas, J. Curr. Pharm. Des. 2017, 23, 1-15. doi:10.2174/1381612823666171017165707

3. Taran, S. A.; Verevkina, K. N.; Feofanov, S. A.; Miroshnikov, A. I. Russ. J. Bioorg. Chem. 2009, 35, 739-745. doi:10.1134/s1068162009060107

4. Mikhailopulo, I. A. Curr. Org. Chem. 2007, 11, 317-335. doi:10.2174/138527207780059330

5. Mikhailopulo, I. A.; Miroshnikov, A. I. Mendeleev Commun. 2011, 21, 57-68. doi:10.1016/j.mencom.2011.03.001

6. Wintersberger, E. Biochem. Soc. Trans. 1997, 25, 303-308. doi:10.1042/bst0250303

7. Tesmer, J. J.; Klem, T. J.; Deras, M. L.; Davisson, V. J.; Smith, J. L. Nat. Struct. Biol. 1996, 3, 74-86. doi:10.1038/nsb0196-74

8. Kim, M.-J.; Whitesides, G. M. Appl. Biochem. Biotechnol. 1987, 16, 95-108. doi:10.1007/bf02798359

9. Scism, R. A.; Stec, D. F.; Bachmann, B. O. Org. Lett. 2007, 9, 4179-4182. doi:10.1021/ol7016802

10. Mikhailopulo, I. A.; Miroshnikov, A. I. ActaNaturae 2010, 2, 36-59.

11. Iglesias, L. E.; Lewkowicz, E. S.; Medici, R.; Bianchi, P.; Iribarren, A. M. Biotechnol. Adv. 2015, 33, 412-434. doi:10.1016/j.biotechadv.2015.03.009

12. Kanagawa, M.; Baba, S.; Ebihara, A.; Shinkai, A.; Hirotsu, K.; Mega, R.; Kim, K.; Kuramitsu, S.; Sampei, G.-i.; Kawai, G. Acta Crystallogr., Sect. F: Struct. Biol. Cryst. Commun. 2010, 66, 893-898. doi:10.1107/s1744309110023079

13. Canyuk, B.; E-Wan, A.; Keawwijit, W.; Nualnoi, T.; Sirisatean, L.; Tansakul, P.; Tanthana, C. Nucleosides, Nucleotides Nucleic Acids 2008, 27, 894-899. doi:10.1080/15257770802146593

14. Miller, R. L.; Ramsey, G. A.; Krenitsky, T. A.; Elion, G. B. Biochemistry 1972, 11, 4723-4731. doi:10.1021/bi00775a014

15. Streeter, D. G.; Miller, J. P.; Robins, R. K.; Simon, L. N. Ann. N. Y. Acad. Sci. 1977, 284, 201-210. doi:10.1111/j.1749-6632.1977.tb21952.x

16. Naesens, L.; Guddat, L. W.; Keough, D. T.; van Kuilenburg, A. B. P.; Meijer, J.; Voorde, J. V.; Balzarini, J. Mol. Pharmacol. 2013, 84, 615-629. doi:10.1124/mol.113.087247

17. Laemmli, U. K. Nature 1970, 227, 680-685. doi:10.1038/227680a0

18. Bradford, M. M. Anal. Biochem. 1976, 72, 248-254. doi:10.1016/0003-2697(76)90527-3

\section{Acknowledgements}

The authors are grateful to Russian Science Foundation (project No. 14-50-00131) for financial support of this work. 


\section{License and Terms}

This is an Open Access article under the terms of the Creative Commons Attribution License

(http://creativecommons.org/licenses/by/4.0). Please note that the reuse, redistribution and reproduction in particular requires that the authors and source are credited.

The license is subject to the Beilstein Journal of Organic Chemistry terms and conditions:

(https://www.beilstein-journals.org/bjoc)

The definitive version of this article is the electronic one which can be found at:

doi:10.3762/bjoc.14.289 